\title{
Research
}

\section{Perceptions and knowledge of self-regulation of paramedics in}

\section{Australia}

Buck Reed DipParamedicSc, BCA, GradCertHIthMgmt, MInt|HIthMgmt'1,2; Leanne Cowin BNurs, MSci, MNurs, PhD; Peter O'Meara BHA, MPP, PhD4; lan Wilson MBBS, PhD, FRACGP2

\author{
Affiliation: \\ 'School of Health Sciences, Western Sydney University, New South Wales \\ 2School of Medicine, University of Wollongong, New South Wales \\ ${ }^{3}$ School of Nursing and Midwifery, Western Sydney University, New South Wales \\ ${ }^{4}$ Department of Paramedicine, Monash University, Melbourne, Victoria
}

https://doi.org/10.33151/ajp.18.963

\section{Abstract}

\section{Background}

Since 2018, paramedics in Australia have been self-regulated under the National Registration and Accreditation Scheme for health practitioners. While paramedics and other health practitioners are self-regulated in many jurisdictions internationally, there has been little study of the impact on practitioners of the introduction of new regulatory frameworks.

\section{Methods}

Paramedics undertook a survey in the month leading up to the commencement of self-regulation collecting both qualitative and quantitative data. The survey was completed by 419 participants. This article explores the analysis of quantitative data. Key results were cross-tabulated with demographic factors.

Results

Participants indicated they had good broad knowledge of the regulatory scheme but were less confident on more detailed aspects. Most believed that patient safety and practitioner accountability would improve with registration, however results were less clear on changes in scope, remuneration or employment opportunities. Questions on identity indicated that the primary factors in paramedic identity construction were employment status, qualifications, and scope with impending registration the least important factor. Overall, $59 \%$ of participants supported self-regulation, however $25 \%$ indicated they held negative views. When cross-tabulated with demographics, years of service and initial qualification (vocational vs. university) showed relationships with support for regulation.

\section{Conclusion}

The introduction of self-regulation represents significant change to both the governance of paramedics and entry to the profession. Uncertainty by some is indicative of the unique nature and impact of the change. However, there is wide agreement that the scheme will increase public safety and accountability, which are the key aims of professional regulation.

Keywords:

professionalism; regulation; identity; registration; self-regulation

Corresponding Author: Buck Reed, b.reed@westernsydney.edu.au 


\section{Introduction}

As paramedicine matures as a health profession, greater regulatory control has been applied to help ensure the safety of the public. Internationally, an increasing number of jurisdictions are adopting self-regulatory frameworks for paramedicine. Likewise, in non-self-regulated jurisdictions, licensing schemes are often used to provide accountability for practice or proof of qualification and currency. In 2018, paramedicine became the 15 th profession to be regulated under Australia's National Registration and Accreditation Scheme (NRAS) for health practitioners $(1,2)$. Before the NRAS, paramedics and their predecessors operated as unregulated health professionals (save ambulance service legislation or internal organisational governance) for over a century. The inclusion of paramedics in the NRAS represents a significant change in the regulation and governance of the profession. This article explores the impact on paramedics from this development through data from a 2018 survey of paramedic perceptions of regulation undertaken in the month before 'participation date', that is, the day paramedic regulation commenced, and analyses the results of the quantitative elements of the survey.

\section{The purpose of regulation and the impact on practitioners}

While it is largely accepted that the principal aim of professional regulation is the protection of the public, there is some debate over the mechanism by which self-regulation achieves this (3). Regulatory schemes, such as the NRAS, provide a formal mechanism to determine entry to a profession, establish boundaries of professional behaviour and provide mechanisms to remedy a range of practitioner-related issues which potentially impact public safety (4-6). Although the mechanisms and functions of registration are well documented, less explored is the impact of regulation on practitioners and their experience of navigating the implementation of new regulatory frameworks. Equally, the concept of regulation, especially in reference to new professions, is often perceived as the imposition of additional layers of bureaucracy (7). The World Health Organization in discussing regulatory frameworks, clarifies:

"The term "professional regulation" is often misunderstood and interpreted as the imposition of bureaucratic rule-bound requirements which constrain the activities of the profession concerned and serve to maintain the isolation and separateness of the professional from the person for whom they care. Nothing could be further from the truth. Professional regulation, or professional governance, as it should, perhaps, more accurately be known, should be an exciting, dynamic framework within which professional standards can be identified in order to serve the main aim of regulation - that of public protection' (8).
The addition of paramedics to the NRAS represents a major change in terms of the governance of paramedics and more existentially in terms of the derivation of their occupational identity, at least on a formal level.

\section{Other professions and regulation}

Many professions have undertaken the transition into a regulatory framework. Medicine in Great Britain began the path to regulation as early as 1421, with the College of Physicians being formed in 1511 (9). Later the Apothecary Act of 1815 and Medical Act of 1858 set clear delineation between qualified and unqualified doctors (10). Following medicine's reforms in the 19th century, several professions moved towards professional regulation in the last part of the 19th century or beginning of the 20th century, for example: dentistry and pharmacy and more broadly engineering and architecture (11). Nursing adopted regulation in most English-speaking countries in the first quarter of the 20th century (12). Many allied health professions (eg. physiotherapy, occupational therapy, chiropractic) grew as professions in the early half of the 20th century and, depending on the jurisdiction, generally established regulatory frameworks in the post-World War II period (13-15).

\section{Studying the impact of regulation}

While there is some work on the legal basis of health professional regulation or descriptions of regulatory frameworks $(16,17)$, there is little research examining the way the practitioners interact with regulatory systems. A handful of disciplines, most notably social work, have considered the implications of regulation within their workforce $(18,19)$. Others have attempted to document the journey of their profession into their current regulatory framework $(20,21)$. Those professions who have been regulated for some time reflect on developments within their regulatory environment $(3,22)$.

The impact of new regulation has rarely been explored, especially through a sociological lens. The instigation of regulatory frameworks is often driven by a perceived need to regulate either in response to sentinel events or as part of the natural development of a profession $(2,9)$. As exploration of the sociology of health professionals is a relatively recent development, many (especially established) professions were already regulated before such research could be applied to their regulatory and professional transitions.

\section{Methods}

\section{Methodology}

This study uses an embedded mixed methods approach grounded in social constructivism. Social constructivism holds that knowledge and beliefs are constructed based on a complex 
series of relationships and influences (23). It is likely that paramedics' perceptions about being regulated are based on a range of influences such as culture, education, knowledge of regulation and previous experiences with regulation. For example, it is hypothesised that views of regulation between state and territorial jurisdictions may differ based on diverse workplace cultures and industrial histories. Likewise, social constructivism is linked to postmodernism which recognises that individuals have unique experiences and worldviews, and resultingly, a diversity of views may exist within a population (24). While surveys have traditionally operated within a positivist or post-positivist construct (25), the design of this survey primarily seeks data about perceptions or worldviews, which is more appropriately situated in a sociological paradigm such as social constructivism.

\section{Survey design}

Data was collected using a survey combining multiple-choice questions (MCQs), matrix multiple-choice (i.e., a single MCQ with multiple topic areas) and free text questions. MCQ and matrix $M C Q$ questions produce a single definitive answer. The survey tool was designed to collect information in support of the research question and sub-questions within the constructivist approach. Qualtrics was the platform used to design and deploy the survey. Distribution was primarily through social media and open for responses over a 30-day period leading up to 'participation date'.

\section{Ethics}

Ethics approval was obtained from the University of Wollongong Human Research Ethics Committee (Approval 2018/462).

The survey was designed to capture different elements of the perceptions and experience of entering regulation plus basic demographic data. The survey was broken down into five sections shown in Table 1

The survey was designed to capture different elements of the perceptions and experience of entering regulation plus basic demographic data. The survey was broken down into five sections shown in Table 1.

Table 1. Survey sections and questions

\begin{tabular}{|c|c|c|}
\hline Section & Questions & Purpose \\
\hline $\begin{array}{l}\text { Knowledge of the } \\
\text { new regulatory } \\
\text { scheme }\end{array}$ & $\begin{array}{l}\text { Six (6) } \\
\text { - } \quad \text { four MCQ } \\
\text { - } \quad \text { two free text }\end{array}$ & $\begin{array}{l}\text { This section explored the self-reported knowledge of participants about the } \\
\text { regulatory scheme for paramedics being implemented in late 2018. The first } \\
\text { three questions explored knowledge of the scheme in general, registration } \\
\text { standards and the process for complaint handling. Question } 4 \text { examined } \\
\text { perceptions of the quality of communication from the regulator leading up to the } \\
\text { commencement of the scheme. The final two questions are free text and will be } \\
\text { reported in a subsequent paper }\end{array}$ \\
\hline $\begin{array}{l}\text { Perceptions of the } \\
\text { new regulatory } \\
\text { scheme }\end{array}$ & $\begin{array}{l}\text { Seven }(7) \\
\text { - } \quad \text { six } M C Q \\
\text { - } \quad \text { one free text }\end{array}$ & $\begin{array}{l}\text { This section asked participants for their perceptions of the regulatory scheme. } \\
\text { Questions } 1 \text { to } 6 \text { asked about changes in patient safety, changes in individual } \\
\text { accountability, changes in fairness of complaint handling, variety of work } \\
\text { opportunities, changes in scope of practice and changes in remuneration } \\
\text { respectively. The final question is free text }\end{array}$ \\
\hline $\begin{array}{l}\text { Impact of the new } \\
\text { regulatory scheme } \\
\text { on the respondent } \\
\text { personally }\end{array}$ & $\begin{array}{l}\text { Five (5) } \\
-\quad \text { three } M C Q \\
-\quad \text { two free text }\end{array}$ & $\begin{array}{l}\text { This section sought participants' views on how the regulatory scheme will } \\
\text { impact them personally. Question } 1 \text { asked about the participant's views on } \\
\text { registration using a five statement range from strongly unsupportive to strongly } \\
\text { supportive. Question } 2 \text { asked if the participant is experiencing concern or } \\
\text { anxiety because of registration. Question } 3 \text { asked about the respondent's } \\
\text { confidence in being registered. The final two questions are free text }\end{array}$ \\
\hline $\begin{array}{l}\text { Impact of the new } \\
\text { regulatory scheme } \\
\text { on paramedic } \\
\text { identity }\end{array}$ & $\begin{array}{l}\text { Five (5) } \\
\text { - } \quad \text { three MCQ } \\
\text { - } \quad \text { one free text } \\
\text { - } \quad \text { one matrix MCQ }\end{array}$ & $\begin{array}{l}\text { This section sought participants' views on how the regulatory scheme will } \\
\text { impact their professional identity and what forms their sense of identity as a } \\
\text { paramedic }\end{array}$ \\
\hline Demographics & $\begin{array}{l}\text { Twelve (12) } \\
\text { - } \quad \text { three number } \\
\text { responses } \\
\text { - } \quad \text { eight MCQ } \\
\text { - } \quad \text { one matrix MCQ }\end{array}$ & $\begin{array}{l}\text { This section collected demographic data about participants including age, } \\
\text { gender, years of service; qualifications; nature of employment; jurisdiction of } \\
\text { practice; membership of professional bodies }\end{array}$ \\
\hline
\end{tabular}


A pilot was undertaken with a convenience sample of 21 participants who completed the survey with additional feedback questions about survey design. Feedback was incorporated into the final version to increase both clarity and brevity of the questions. Pilot data were not included in analysis, although participants were invited to complete the final version of the survey.

\section{Population}

At the time of the survey, the estimated number of paramedics in Australia was 15,000 . This figure is based on the 13,727 people that self-reported in the 2011 Census the occupation of 'ambulance officer' or 'intensive care paramedic' plus practitioners who report in other categories (e.g., military paramedics primarily report as Defence Force members). As paramedics were not yet operational in the NRAS at the time of the survey, Census data was the best available method of estimating workforce size (26). This figure encompasses estimated workforce growth since 2011 from increases in university graduates and staffing enhancements by major employers. Estimates were also referenced against workforce figures from the Council of Ambulance Authorities (27). Based on this estimated population, seeking a $95 \%$ confidence level, and accepting a $5 \%$ margin for error, a target survey population was calculated at 375 respondents. Inclusion criteria for this survey were that participants self-identified as paramedics and principally practised in Australia.

\section{Data analysis}

Data analysis was undertaken utilising several methods. Qualtrics itself provides significant amounts of data reporting, primarily around percentages and populations. Likewise, crosstabulations were undertaken using Qualtrics data analysis functions, especially to produce tables. Other basic calculations were undertaken in Microsoft Excel where the survey data was exported from Qualtrics. These calculations included means, some percentages and graphing of demographic data. This was especially used for demographic data. Chi-squared tests were undertaken using an online calculator for social research statistics

(https://www.socscistatistics.com/tests/chisquare2/default2.asp $\mathrm{x})$.

\section{Results}

\section{Responses and demographics}

There were 492 survey responses, with 419 fully completed (85\%). The 73 partially completed responses were excluded from analysis. Geographically, New South Wales was over- represented while Queensland and Victoria were underrepresented. Responses from other states and territories were relatively proportionate to their paramedic workforce. Approximately two-thirds of respondents were male, and onethird were female, representing slightly more males compared to workforce data (Table 2) (28).

Table 2. Respondents by jurisdiction and gender

\begin{tabular}{|l|l|l|l|}
\hline & $\begin{array}{l}\text { Number } \\
\text { in survey }\end{array}$ & $\begin{array}{l}\% \text { of } \\
\text { survey }\end{array}$ & $\begin{array}{l}\% \text { of } \\
\text { workforce } \\
(28)\end{array}$ \\
\hline Jurisdiction & 17 & $4 \%$ & $1.5 \%$ \\
\hline $\begin{array}{l}\text { Australian Capital } \\
\text { Territory }\end{array}$ & 146 & $35 \%$ & $25.4 \%$ \\
\hline New South Wales & 5 & $1 \%$ & $1.1 \%$ \\
\hline Northern Territory & 77 & $18 \%$ & $26.42 \%$ \\
\hline Queensland & 38 & $9 \%$ & $7.1 \%$ \\
\hline South Australia & 23 & $5 \%$ & $2.61 \%$ \\
\hline Tasmania & 84 & $20 \%$ & $29.21 \%$ \\
\hline Victoria & 29 & $7 \%$ & $5.9 \%$ \\
\hline Western Australia & 131 & $31.3 \%$ & $40.2 \%$ \\
\hline Gender & 283 & $67.5 \%$ & $59.7 \%$ \\
\hline Male & 5 & $1.2 \%$ & $0.1 \%$ \\
\hline Female & $100 \%$ & $100 \%$ \\
\hline Intersex/indeterminate & 519 & & \\
\hline Total & $5 \%$ & $5 \%$ \\
\hline
\end{tabular}

The age distribution of the survey group was broadly representative of the Australian paramedic workforce. Notable exceptions are a slightly higher participation of the 45 to 55 years age bracket and slightly lower participation by paramedics less than 30 years of age (Figure 1). 


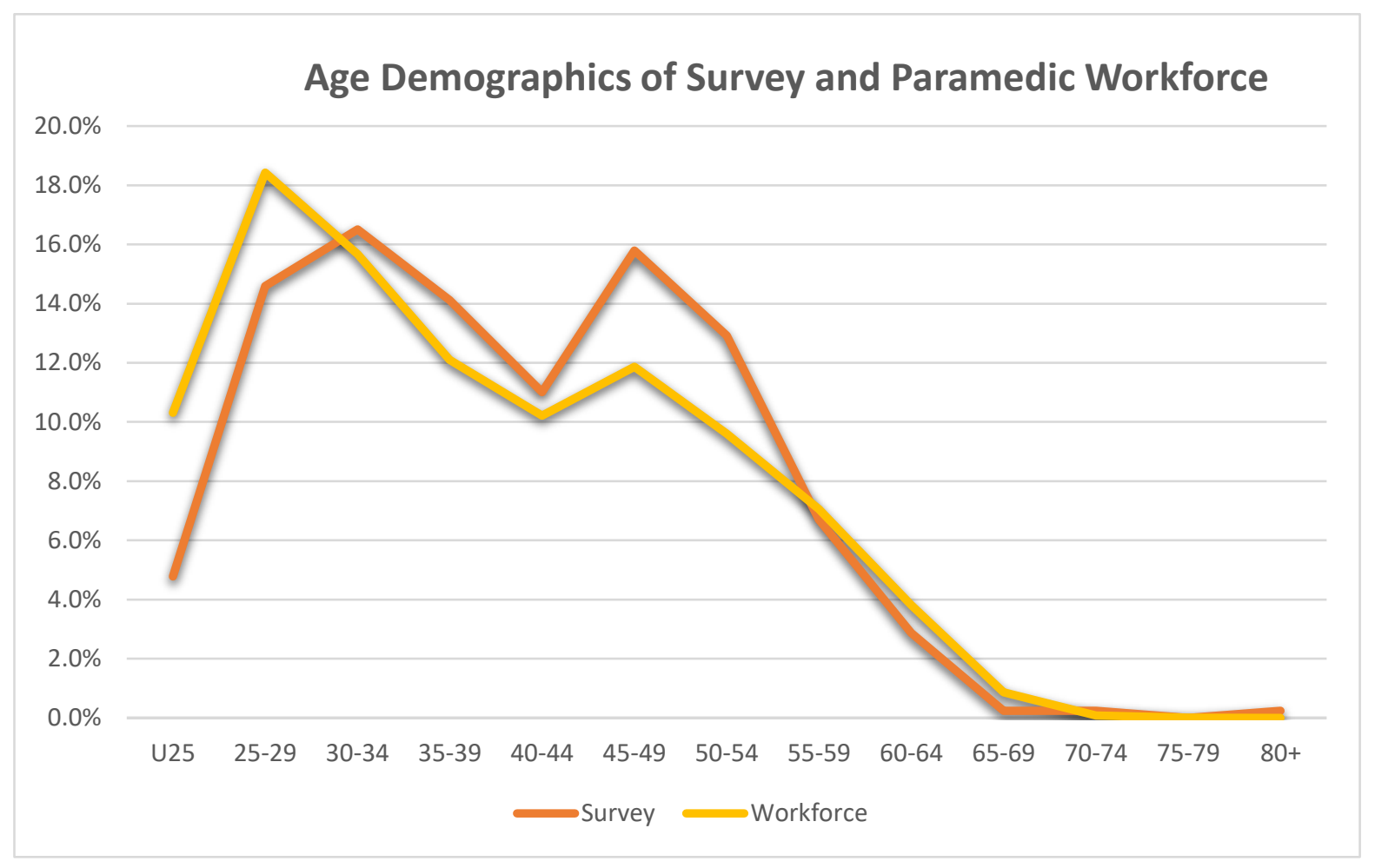

Figure 1. Age of respondents compared to age of workforce (28)

Table 3. Question K1-3, participant knowledge of the registration scheme (K1), registration standards (K2) and complaint handling (K3)

\begin{tabular}{|l|l|l|l|l|l|}
\hline & $\begin{array}{l}\text { I have no } \\
\text { knowledge of it }\end{array}$ & $\begin{array}{l}\text { I have a little } \\
\text { knowledge of it }\end{array}$ & $\begin{array}{l}\text { I have some } \\
\text { knowledge of it }\end{array}$ & $\begin{array}{l}\text { I have a good } \\
\text { knowledge of it }\end{array}$ & $\begin{array}{l}\text { I have an } \\
\text { excellent } \\
\text { knowledge of it }\end{array}$ \\
\hline $\begin{array}{l}\text { K1: How would you describe your } \\
\text { knowledge of the upcoming registration } \\
\text { scheme for paramedics under the NRAS } \\
\text { overall? }\end{array}$ & $5(0.95 \%)$ & $47(8.59 \%)$ & $187(37.95 \%)$ & $205(42.24 \%)$ & $48(10.26 \%)$ \\
\hline $\begin{array}{l}\text { K2: How would you describe your } \\
\text { knowledge of the Registration Standards } \\
\text { applied to paramedics under the } \\
\text { registration scheme? }\end{array}$ & $25(4.77 \%)$ & $77(14.80 \%)$ & $183(36.28 \%)$ & $168(35.80 \%)$ & $39(8.35 \%)$ \\
\hline $\begin{array}{l}\text { K3: How would you describe your } \\
\text { knowledge of the process for managing } \\
\text { serious complaints against paramedics } \\
\text { (in your state or territory) once } \\
\text { registration commences? }\end{array}$ & $134(26.97 \%)$ & $149(28.88 \%)$ & $146(29.59 \%)$ & $54(12.41 \%)$ & $9(2.15 \%)$ \\
\hline
\end{tabular}


Participants were asked their perception of how efficiently information regarding registration was disseminated by the PBA. Just under half of respondents $(221 / 45 \%)$ reported that information was not disseminated adequately, while 271 respondents $(55 \%)$ reported they found information dissemination to be adequate or good.

\section{Perceptions of the Registration Scheme}

When asked about their perceptions of how registration would change elements of paramedic practice, most participants believed that patients would be as safe or safer and that paramedics would be more accountable. However, other areas such as remuneration and scope were unlikely to change (Table 4).

Table 4. Question P1-6, perceived impact of registration on patient safety (P1), practitioner accountability (P2), fairness of complaint handling (P3), employment opportunities (P4), scope (P5) and remuneration (P6)

\begin{tabular}{|c|c|c|c|c|c|c|}
\hline Question & $\begin{array}{l}\text { Substantially } \\
\text { less (or will } \\
\text { substantially } \\
\text { decrease) }\end{array}$ & $\begin{array}{l}\text { Slightly } \\
\text { less (or will } \\
\text { slightly } \\
\text { decrease) }\end{array}$ & No change & $\begin{array}{l}\text { Slightly } \\
\text { more (or } \\
\text { will slightly } \\
\text { increase) }\end{array}$ & $\begin{array}{l}\text { Substantially } \\
\text { more (or will } \\
\text { substantially } \\
\text { increase) }\end{array}$ & $\begin{array}{l}\text { Insufficient } \\
\text { information } \\
\text { to decide }\end{array}$ \\
\hline $\begin{array}{l}\text { P1: Do you think that patients will be } \\
\text { safer once paramedics are } \\
\text { registered? (this refers to their overall } \\
\text { safety, both in terms of their risk from } \\
\text { poor clinical practice AND their risk } \\
\text { from poor conduct or } \\
\text { unqualified/underqualified } \\
\text { practitioners)? }\end{array}$ & $\begin{array}{c}4 \\
(0.95 \%)\end{array}$ & $\begin{array}{c}5 \\
(1.1 \%)\end{array}$ & $\begin{array}{c}198 \\
(47.36 \%)\end{array}$ & $\begin{array}{c}102 \\
(24.34 \%)\end{array}$ & $\begin{array}{c}95 \\
(22.67 \%)\end{array}$ & $\begin{array}{c}15 \\
(3.58 \%)\end{array}$ \\
\hline $\begin{array}{l}\text { P2: Do you think that paramedics will } \\
\text { be more individually accountable } \\
\text { once paramedics are registered } \\
\text { compared to current levels of } \\
\text { individual accountability? }\end{array}$ & $\begin{array}{c}1 \\
(0.24 \%)\end{array}$ & $\begin{array}{c}4 \\
(0.95 \%)\end{array}$ & $\begin{array}{c}76 \\
(18.14 \%)\end{array}$ & $\begin{array}{c}104 \\
(24.82 \%)\end{array}$ & $\begin{array}{c}223 \\
(53.22 \%)\end{array}$ & $\begin{array}{c}11 \\
(2.63 \%)\end{array}$ \\
\hline $\begin{array}{l}\text { P3: Paramedic registration changes } \\
\text { the way major complaints against } \\
\text { paramedics are handled. How do you } \\
\text { think this change will affect the } \\
\text { fairness of this process (if at all)? }\end{array}$ & $\begin{array}{c}55 \\
(13.13 \%)\end{array}$ & $\begin{array}{c}66 \\
(15.75 \%)\end{array}$ & $\begin{array}{c}46 \\
(10.98 \%)\end{array}$ & $\begin{array}{c}76 \\
(18.14 \%)\end{array}$ & $91(21.72 \%)$ & $\begin{array}{c}85 \\
(20.29 \%)\end{array}$ \\
\hline $\begin{array}{l}\text { P4: Do you think that the variety of } \\
\text { employment opportunities for } \\
\text { paramedics (that is, the roles and } \\
\text { organisations paramedics can work } \\
\text { in) will change once paramedics are } \\
\text { registered? }\end{array}$ & $20(4.77 \%)$ & $16(3.82 \%)$ & $\begin{array}{c}130 \\
(31.03 \%)\end{array}$ & $\begin{array}{c}125 \\
(29.83 \%)\end{array}$ & $\begin{array}{c}105 \\
(25.05 \%)\end{array}$ & $\begin{array}{c}23 \\
(5.49 \%)\end{array}$ \\
\hline $\begin{array}{l}\text { P5: Do you think that the scope of } \\
\text { practice for paramedics (ie. the range } \\
\text { of clinical treatment options) will } \\
\text { change once paramedics are } \\
\text { registered? }\end{array}$ & $\begin{array}{c}10 \\
(2.39 \%)\end{array}$ & $\begin{array}{c}12 \\
(2.86 \%)\end{array}$ & $\begin{array}{c}231 \\
(55.13 \%)\end{array}$ & $\begin{array}{c}96 \\
(22.19 \%)\end{array}$ & $\begin{array}{c}36 \\
(8.59 \%)\end{array}$ & $\begin{array}{c}34 \\
(8.11 \%)\end{array}$ \\
\hline $\begin{array}{l}\text { P6: Do you think that the level of } \\
\text { remuneration for paramedics (how } \\
\text { much paramedics are paid) will } \\
\text { change once paramedics are } \\
\text { registered? }\end{array}$ & $\begin{array}{c}7 \\
(1.67 \%)\end{array}$ & $\begin{array}{c}15 \\
(3.58 \%)\end{array}$ & $\begin{array}{c}287 \\
(68.50 \%)\end{array}$ & $\begin{array}{c}73 \\
(17.42 \%)\end{array}$ & $\begin{array}{c}10 \\
(2.39 \%)\end{array}$ & $\begin{array}{c}27 \\
(6.4 \%)\end{array}$ \\
\hline
\end{tabular}




\section{Impact of the Registration Scheme on paramedics}

In Question T1, participants were asked for their overall view of registration. Negative views were reported in $25.53 \%$ of respondents whereas $13.60 \%$ had a neutral view, $59.19 \%$ had a positive view and $1.67 \%$ were undecided. Registration represented changes in the way that people can identify as paramedics and creates a new process for formal acceptance into the profession. While it was expected that most practising paramedics would enter the NRAS seamlessly, people identifying as paramedics held a range of experiences and qualifications which had not previously been used to determine their inclusion into, or exclusion from, the profession. As such, it was likely some people practising as paramedics would have concerns about meeting the new standards. Participants were asked if they had concerns or anxiety around registration and the registration process. Respondents were asked to assign themsleves to one of five self-reported classiciations of concern or anxiety. Almost half of the respondents (46\%) indicated that they did not have any concerns about the registration process. Another $46 \%$ indicated that they had some level of concern. Eight percent of respondents indicated that they had physical symptoms of anxiety. In those who reported anxiety over registration, $12 \%$ reported the symptoms were severe and causing events such as panic attacks.

When asked about their confidence in being granted registration, $81 \%$ had either been granted registration (the application process commenced several months before participation date, with approximately $40 \%$ of respondents accepted at the time of the survey) or were confident of receiving it. However, $14 \%$ were only slightly or moderately confident and $3 \%$ believed they would not be granted registration. One percent had either chosen not to apply because they believed they would be declined or had already been declined registration.

\section{Perceptions of the impact of the Registration Scheme on professional identity}

One of the core elements of self-regulation is the capacity of the profession to determine who is or is not a member (29). The survey asked paramedics how they constructed their identity and the importance of five key elements of identity including professional registration qualifications, employment, community of practice and scope (Table 5).

\section{Employment rated as the most important element of professional identity with $80 \%$ of respondents saying it was extremely or very important. Around $37 \%$ of respondents indicated scope and qualifications were very important with $32 \%$ and $28 \%$ respectively considering those elements to be extremely important. Conversely membership of a community of practice varied in importance and $41 \%$ of respondents indicated that registration was not at all important.}

Question T3 asked if being registered would likely change their identity. Responses were mixed, with $61 \%$ of respondents believing that their professional identity would "definitely not" or "probably not" change. Approximately $24 \%$ of respondents believed their sense of professional identity would change and $10.5 \%$ reported being unsure. Considering whether registration would change their internal identity as seen by other paramedics, most respondents (68\%) indicated that little or no change would occur. Respondents reported higher confidence in their professional identity changing among other health disciplines with $36 \%$ believing this would be the case.

Table 5. Question T1, factors impacting paramedic identity

\begin{tabular}{|l|l|c|c|c|c|}
\hline & $\begin{array}{l}\text { Not important } \\
\text { to my sense } \\
\text { of who I am } \\
\text { as a } \\
\text { paramedic }\end{array}$ & $\begin{array}{l}\text { Slightly } \\
\text { important to } \\
\text { my sense of } \\
\text { who I am as } \\
\text { a paramedic }\end{array}$ & $\begin{array}{l}\text { Somewhat } \\
\text { important to } \\
\text { my sense of } \\
\text { who I am as a } \\
\text { paramedic }\end{array}$ & $\begin{array}{l}\text { Very important } \\
\text { to my sense of } \\
\text { who I am as a } \\
\text { paramedic }\end{array}$ & $\begin{array}{l}\text { Extremely } \\
\text { important to } \\
\text { my sense of } \\
\text { who I am as a } \\
\text { paramedic }\end{array}$ \\
\hline Professional registration & $172(41.05 \%)$ & $52(12.41 \%)$ & $88(21.00 \%)$ & $73(17.42 \%)$ & $34(8.11 \%)$ \\
\hline $\begin{array}{l}\text { The qualification you obtained to be a } \\
\text { paramedic }\end{array}$ & $43(10.26 \%)$ & $29(6.92 \%)$ & $76(18.14 \%)$ & $155(36.99 \%)$ & $116(27.68 \%)$ \\
\hline Being employed as a paramedic & $18(4.30 \%)$ & $12(2.86 \%)$ & $53(12.65 \%)$ & $156(37.23 \%)$ & $180(42.96 \%)$ \\
\hline Being part of a community of practitioners & $69(16.47 \%)$ & $47(11.22 \%)$ & $114(27.21 \%)$ & $109(26.01 \%)$ & $80(19.09 \%)$ \\
\hline Your scope of practice & $29(6.92 \%)$ & $23(5.49 \%)$ & $78(18.62 \%)$ & $154(36.75 \%)$ & $135(32.22 \%)$ \\
\hline
\end{tabular}




\section{Impact of demographics on perceptions of registration}

One of the assumptions of the implementation of paramedic regulation in Australia was that the move to regulation would be more welcomed by younger practitioners and those with baccalaureate-level entry to practice education. Likewise, it was thought regulation would be less welcomed by those who were older or more experienced practitioners and those trained through vocational systems. However, this premise has not previously been tested. Experienced paramedics are often seen as change-adverse, and this underpinned this assumption $(30,31)$. When demographic data was crosstabulated with key survey questions, it shows a less dichotomous relationship between views of regulation. There was some correlation between initial education and views of regulation, however there was a bimodal relationship with years of practice where those at the newest and most experienced ends of the spectrum expressed the most positive views of regulation.
Each of these key variables (years of service, initial qualification, highest qualification, and state) were tested using a chi-squared test of independence. There was a positive association between years of practice and support of registration $(X 2(d f=12, N=409)=33.40, p<0.001$ where $p$ was significant at $<0.05$ ). Of interest is that support for registration was strongest in the $20+$ years of practice cohort and the less than 5 years of practice cohort, suggesting a non-linear relationship between years of service and support for registration. The initial education of the paramedic is also an indicator of support for registration ( $\mathrm{X} 2(\mathrm{df}=4, \mathrm{~N}=412)=32.17$, $p<0.001$ where $p$ was significant at $<0.05)$. For example, strong support was $20.8 \%$ higher in the university-trained cohort than the expected result based on the survey mean and was $29.6 \%$ lower than expected in the vocationally trained cohort.

Table 6. Years of practice, initial qualification and jurisdiction of practice cross-tabulated with support for registration

\begin{tabular}{|c|c|c|c|c|c|c|c|c|c|c|c|c|c|c|}
\hline \multirow{2}{*}{\multicolumn{2}{|c|}{\begin{tabular}{l|r} 
unst \\
Years of practice
\end{tabular}}} & $\begin{array}{l}\text { gly } \\
\text { ortive }\end{array}$ & \multicolumn{2}{|c|}{$\begin{array}{c}\text { Slightly } \\
\text { unsupportive }\end{array}$} & \multicolumn{2}{|c|}{$\begin{array}{c}\text { Neither } \\
\text { supportive } \\
\text { nor un- } \\
\text { supportive }\end{array}$} & \multicolumn{2}{|c|}{$\begin{array}{c}\text { Slightly } \\
\text { supportive }\end{array}$} & \multicolumn{2}{|c|}{$\begin{array}{c}\text { Strongly } \\
\text { supportive }\end{array}$} & \multicolumn{2}{|c|}{$\begin{array}{l}\text { Insufficient } \\
\text { information }\end{array}$} & Total & \multirow[t]{2}{*}{$\begin{array}{c}\text { Percentage } \\
\text { of total } \\
\text { sample }\end{array}$} \\
\hline & & & & & & & & & & & & & & \\
\hline $0-5$ & 4 & $3 \%$ & 22 & $17 \%$ & 13 & $10 \%$ & 26 & $20 \%$ & 60 & $47 \%$ & 2 & $2 \%$ & 127.0 & $30.3 \%$ \\
\hline $6-10$ & 10 & $11 \%$ & 14 & $16 \%$ & 17 & $19 \%$ & 16 & $18 \%$ & 30 & $33 \%$ & 3 & $3 \%$ & 90.0 & $21.5 \%$ \\
\hline $11-20$ & 23 & $21 \%$ & 10 & $9 \%$ & 18 & $16 \%$ & 23 & $21 \%$ & 37 & $33 \%$ & 1 & $1 \%$ & 112.0 & $26.7 \%$ \\
\hline $21+$ & 13 & $15 \%$ & 12 & $14 \%$ & 7 & $8 \%$ & 10 & $11 \%$ & 44 & $51 \%$ & 1 & $1 \%$ & 87.0 & $20.8 \%$ \\
\hline No answer & 0 & $0 \%$ & 0 & $0 \%$ & 1 & $33 \%$ & 0 & $0 \%$ & 2 & $67 \%$ & 0 & $0 \%$ & 3.0 & $0.7 \%$ \\
\hline \multicolumn{15}{|c|}{ Initial qualification (for entry to practice) } \\
\hline Vocational & 31 & $18 \%$ & 36 & $21 \%$ & 26 & $15 \%$ & 27 & $16 \%$ & 50 & $29 \%$ & 3 & $2 \%$ & 173 & $41 \%$ \\
\hline University & 19 & $8 \%$ & 21 & $9 \%$ & 31 & $13 \%$ & 49 & $20 \%$ & 122 & $50 \%$ & 4 & $2 \%$ & 246 & $59 \%$ \\
\hline \multicolumn{15}{|c|}{ Primary jurisdiction of practice } \\
\hline NSW & 20 & $14 \%$ & 24 & $16 \%$ & 24 & $16 \%$ & 26 & $18 \%$ & 50 & $34 \%$ & 2 & $1 \%$ & 146.0 & $34.8 \%$ \\
\hline VIC & 10 & $12 \%$ & 7 & $8 \%$ & 9 & $11 \%$ & 19 & $23 \%$ & 38 & $45 \%$ & 1 & $1 \%$ & 84.0 & $20.0 \%$ \\
\hline QLD & 7 & $9 \%$ & 8 & $10 \%$ & 9 & $12 \%$ & 14 & $18 \%$ & 36 & $47 \%$ & 3 & $4 \%$ & 77.0 & $18.4 \%$ \\
\hline$S A$ & 3 & $8 \%$ & 8 & $21 \%$ & 7 & $18 \%$ & 4 & $11 \%$ & 15 & $39 \%$ & 1 & $3 \%$ & 38.0 & $9.1 \%$ \\
\hline WA & 6 & $21 \%$ & 7 & $24 \%$ & 2 & $7 \%$ & 5 & $17 \%$ & 9 & $31 \%$ & 0 & $0 \%$ & 29.0 & $6.9 \%$ \\
\hline TAS & 2 & $9 \%$ & 1 & $4 \%$ & 5 & $22 \%$ & 2 & $9 \%$ & 13 & $57 \%$ & 0 & $0 \%$ & 23.0 & $5.5 \%$ \\
\hline ACT & 2 & $12 \%$ & 1 & $6 \%$ & 1 & $6 \%$ & 6 & $35 \%$ & 7 & $41 \%$ & 0 & $0 \%$ & 17.0 & $4.1 \%$ \\
\hline NT & 0 & $0 \%$ & 1 & $20 \%$ & 0 & $0 \%$ & 0 & $0 \%$ & 4 & $80 \%$ & 0 & $0 \%$ & 5.0 & $1.2 \%$ \\
\hline
\end{tabular}




\section{Discussion}

\section{Knowledge of the Registration Scheme}

Generally, paramedics felt that they had a good knowledge of registration, the process, and the implications of the scheme overall. However, questions that dealt with more detailed elements of registration such as standards or complaintshandling showed lower levels of confidence. The perception of the process of information dissemination by the PBA is likely to be influenced by a range of factors. These will be explored in a subsequent paper examining the qualitative data from the survey. Given the novel experience of having an external regulator and the complexity of paramedic culture, which has traditionally been change-adverse, it was expected that navigating the new registration scheme and integrating it into the profession would not be without challenges $(30,32,33)$.

\section{Perceptions of the Registration Scheme}

The perception of the impact of registration on the profession varied based on the type of impact being discussed.

Respondents felt their personal circumstances, such as remuneration and scope were unlikely to change. However, most respondents felt paramedics would be more accountable and patients would be as safe or safer, suggesting that these core elements of regulation would be achieved. Views about complaints handling were mixed and with $20 \%$ suggesting they did not have enough information to form an opinion. This suggests that without having seen the complaints process in action, the fairness of the process was open to speculation. It is noteworthy that to this point, complaints about paramedics have been regulated primarily by employers rather than by the profession itself through a regulatory authority (2).

\section{Impact of the Registration Scheme on paramedics}

Sixty percent of respondents were positive towards registration. However, approximately one-quarter of respondents held negative views. The nature of these will, again, likely be borne out of the subsequent qualitative analysis of data from this survey. However, the change-resistant nature of the profession may be an underpinning element in this view $(30,33-35)$. Another possibility is that some paramedics, having spent their careers to date regulated through internal employment mechanisms, find less utility in external regulation (2). A traditional role of regulation, it has been argued, is the creation of professional monopolisation of services (5). Again, this is a situation already experienced by Australian paramedics for over a century in most aspects of their current roles through the existence of structural government monopolies of service provision and inherent control over their work and technologies (36).

The impact of years of service and education on views of registration show a complex relationship between paramedics and their views of regulation. For example, paramedics with 20 years or more of service are likely to be almost exclusively vocationally trained yet as a cohort hold the highest level of support for regulation. While this may seem initially counterintuitive based on the data, it recognises that longevity in the profession may both increase the likelihood of having engaged in further education or holding a more refined philosophical view of the profession.

The question about concerns and anxiety holds further interest. While around half of respondents held no concerns before regulation, the fact that half report some concern and $8 \%$ of respondents experience clinical signs of anxiety shows that the introduction of regulation is more than an administrative process. One of the key elements of regulation is that it shifts the legal right to identify oneself as a paramedic from employment status or practitioner self-identification to a community of practice and/or regulator (29). Given that $4 \%$ of respondents either had already been denied registration or believed they would not be registered, that is a quantifiable number of practitioners who will be faced with significant identity transition because of the new regulatory framework. All practitioners would have undertaken some process of socialisation to create their paramedic professional identity. In this situation, identity relies on inclusion within a group (37). The exclusion, or potential exclusion, from that group creates the potential of an existential crisis in practitioners who now face an unknown process with an uncertain outcome around whether they can continue to embrace an identity legally and ethically they may have held for some time.

\section{Perceptions of the impact of the Registration Scheme on professional identity}

When asked about their current sense of identity, respondents primarily indicated that their employment followed by their scope of practice have the largest impact on their identity. In a sense these elements are the most tangible and support a notion of identity through being engaged in a profession in a practical way and 'doing' the tasks and roles associated with that profession $(38,39)$. Equal with scope of practice is qualification which also provides a sense of a journey with a tangible outcome or a milestone which is reached creating a clear transition point from student to practitioner. Registration is reported to have the least impact on professional identity, however this came with the 
caveat that when the question was asked, the regulatory system had not yet begun, so practising as a registered health professional was still a theoretical construct to almost all Australian paramedics. The following question, which asked if respondents felt their identity would change because of registration, saw the majority report it would not. This is likely because it required speculation of how one would construct their identity in the future in reference to something which had not yet occurred. Perception of both internal (other paramedics) and external (other health professionals) views of identity may reflect that within the community of practice, regulation will have limited impact on identity, however, by bringing paramedics into the same regulatory framework as other health professionals there may be a greater sense of parity.

\section{Conclusion}

Before the implementation of the regulatory framework, paramedics seemed unsure of many of the more speculative impacts of the scheme or the operation of the more detailed elements. There does seem to be agreement that regulation through the NRAS will increase accountability and safety, which is the primary aim of the regulatory process. Paramedics have not been regulated in this way previously and have relied on largely occupational identity and governance to establish professional norms and provide a degree of accountability. To shift this accountability to a regulatory body representing the interests of the community is a significant paradigm shift for paramedics.

The results of this study give a sense of the range of perceptions and views which each paramedic has about regulation. While most paramedics seem to favour the new regulatory environment, there is a clear group who do not. There are also significant variances in paramedics reported knowledge of the scheme, especially the more detailed elements of the operation of the scheme. Likewise, their views of the impact regulation will have also varied. What's more, there are clear trends in the demographics associated with different positions, where those trained in universities view regulation more favourably compared to those trained vocationally, and likewise those in mid-career are more resistant than both those at the beginning or those with substantial experience. This highlights the diversity of views on regulation and supports the premise that paramedicine is a heterogeneous collective of sub-cultures with potentially wideranging worldviews.
This study performs two important tasks. It provides us with insights into the perceptions of members of a profession facing an impending regulatory change. In addition, this snapshot of paramedic perceptions provides a benchmark for future studies to measure the evolution of a profession as it navigates a new regulatory environment. There has been little study of the transition of a profession into a regulatory framework, especially as many professions have been regulated for decades, if not centuries, before studies of professions entered academic realms. The opportunity to study a relatively new profession as it evolves through its occupational and regulatory growth is significant. How paramedics navigate the new regulatory environment and how it will impact on professional identity and culture are yet to be seen. This study provides a clear picture of the state of the Australian paramedic profession before entering its next phase of evolution and may provide guidance to other jurisdictions following Australia in their regulation journeys.

\section{Competing interests}

The authors declare no competing interests. Each author of this paper has completed the ICMJE conflict of interest statement.

\section{References}

1. Gough S. Welcoming paramedics into the National Registration and Accreditation Scheme. Australasian Journal of Paramedicine 2018;15.

2. Moritz $D$. The regulatory evolution of paramedic practice in Australia. J Law Med 2018;25:765-81.

3. Waring J. Adaptive regulation or governmentality: patient safety and the changing regulation of medicine. Sociol Health IIIn 2007;29:163-79.

4. Knox S, Batt AM. Professionalization of Paramedics - The role of regulation and registration. Canadian Paramedicine 2018;41:6-8.

5. Freidson $E$. The reorganization of the professions by regulation. Law and Human Behavior 1983;1:279-90.

6. Irvine SD. Professionalism, professional identity, and licensing and accrediting bodies. In: Cruess RL, Cruess SR, Steinert $\mathrm{Y}$, editors. Teaching medical professionalism: supporting the development of a professional identity. 2nd edn. Cambridge, UK: Cambridge University Press; 2016. p. 201-16.

7. Bennett B. Australia's national registration and accreditation scheme for health practitioners: a national approach to polycentric regulation? Sydney Law Review 2018;40:159-81. 
8. World Health Organization. Nursing and midwifery: a guide to professional regulation. Cairo, Egypt: World Health Organisation; 2002, p. 36. Available at: https://apps.who.int/iris/handle/10665/119665 [Accessed 20 April 2021].

9. Raach JH. English medical licensing in the early seventeenth century. Yale J Biol Med 1944;16:267-88.

10. Roberts MJD. The politics of professionalization: MPs, medical men, and the 1858 Medical Act. Med Hist 2009;53:37-56.

11. Anon. Professional registration. Nature 1930;126:637.

12. Fealy GM, Carney M, Drennan J, et al. Models of initial training and pathways to registration: a selective review of policy in professional regulation. J Nurs Manag 2009;17:7308.

13. Andersen $L T$. The history of occupational therapy: the first century. Reed KL, editor. Thorofare, NJ: SLACK Incorporated, 2017, p. 416.

14. Fornasier R. A century-long struggle towards professionalism. Key factors in the growth of the physiotherapists' role in the United States, from subordinated practitioners to autonomous professionals. Management \& Organizational History 2017;12:142-62.

15. Keating J. Milestones in the history of chiropractic. Dynamic Chiropractic 2006;24:35-7.

16. Bolton SP. National registration and accreditation scheme for chiropractors. Chiropractic Journal of Australia 2010;40:45.

17. Bryce J, Foley E. Review of the national registration and accreditation scheme. Aust Nurs Midwifery J 2014;22:17.

18. Beddoe L. Continuing education, registration and professional identity in New Zealand social work. Int Soc Work 2015;58:165-74.

19. Beddoe L, Duke J. Registration in New Zealand social work: the challenge of change. ibid. 2009;52:785-97.

20. Coburn D. State authority, medical dominance, and trends in the regulation of the health professions: the Ontario case. Soc Sci Med 1993;37:841-50.

21. Gibbs V. The long and winding road to achieving professional registration for sonographers. Radiography 2013;19:164-7.

22. Salter $B$. Who rules? The new politics of medical regulation. Soc Sci Med 2001;52:871-83.

23. Keaton SA, Bodie GD. Explaining social constructivism. Commun Teach 2011;25:192-6.

24. Liamputtong P. Qualitative research methods. 4th ed. Melbourne, Australia: Oxford University Press; 2013, p. 439.

25. Groves RM, Fowler FJ, Couper M, et al. Survey methodology. 2nd edn. Hoboken, N.J: Wiley; 2009, p. 496.
26. Paramedics Australasia. Paramedics in the 2011 Census. Melbourne, Australia: Paramedics Australasia; 2012.

27. Council of Ambulance Authorities. Annual Report 2017/18.

Melbourne, Australia: Council of Ambulance Authorities; 2018 p. 19. Available at: www.caa.net.au/files/CAA_Annual_Report_2017-18.pdf [Accessed 20 April 2021].

28. Paramedicine Board of Australia. Registrant data table September 2019. Melbourne, Australia: Paramedicine Board of Australia; 2019. Available at: www.paramedicineboard.gov.au/News/Statistics.aspx [Accessed 20 April 2021].

29. Reed B. Professions and professionalism. In: Moritz D, editor. Paramedic law and regulation in Australia. First edn. Pyrmont, Australia: Thomson Reuters (Professional) Australia; 2019, p. 107-26.

30. Wankhade P, Heath G, Radcliffe J. Cultural change and perpetuation in organisations: evidence from an English emergency ambulance service. Public Management Review 2018;20:923-48.

31. Wankhade P. Different cultures of management and their relationships with organizational performance: evidence from the UK ambulance service. Public Money \& Management 2012;32:381-8.

32. Wankhade P, Radcliffe J. Organisational and professional cultures: an ambulance perspective. In: Wankhade $P$, Mackway-Jones K, editors. Ambulance Services. Switzerland: Springer Cham; 2015, p. 65-80.

33. McCann L, Granter E. Beyond 'blue-collar professionalism': continuity and change in the professionalization of uniformed emergency services work. Journal of Professions and Organization 2019;6:213-32.

34. Wankhade P. Staff perceptions and changing role of prehospital profession in the UK ambulance services: an exploratory study. International Journal of Emergency Services 2016;5:126-44.

35. Dempsey CM. The ambulance service culture: a UK paramedic's perspective. Australasian Journal of Emergency Care 1999;6:17-23.

36. McIntyre D. Technological determinism: a social process with some implications for ambulance paramedics. Australasian Journal of Paramedicine 2003;1.

37. Hafferty FW. Socialization, professionalism and professional identity formation. In: Cruess RL, Cruess SR, Steinert $Y$, editors. Teaching medical professionalism: supporting the development of a professional identity. Second edn. Cambridge, United Kingdom Cambridge University Press; 2016. p. 54-67. 
38. Ewing R, Smith D. Doing, knowing, being and becoming: the nature of. In: Higgs J, Titchen D, editors. Professional practice in health, education and the creative arts. Carlton, Australia: Blackwell Science; 2008, p. 16-28.
39. O'Meara P. So how can we frame our identity? Journal of Paramedic Practice 2011;3:57. 